\title{
Editorial
}

La creación del Instituto de Investigaciones Arqueológicas "R. P. Gustavo Le Paige s.j.", dependiente de la Universidad del Norte, localizado en San Pedro de Atacama, ha permitido la reactivación de la serie Estudios Atacameños. Recientemente se editó el volumen 7 dedicado a las Actas del "Primer simposio de arqueología atacameña", celebrado en San Pedro de Atacama entre el 10 y el 15 de enero de 1983.

Ahora se entregan a la comunidad científica nacional e internacional las ponencias recibidas a raíz del "Seminario-Taller sobre tecnología paleoindia", organizado en Antofagasta por esta casa de estudios en conjunto con el Instituto Smithsoniano de Washington, entre el 21 y el 29 de octubre de 1978.

En este número se han reunido diversos estudios de sitios arqueológicos con ocupaciones de cazadores recolectores ubicados al sur de la línea ecuatorial. Se han ordenado para una lectura más fluida, desde la vertiente atlántica al Pacífico.

Estos estudios ponen de manifiesto la naturaleza de diversas ocupaciones humanas constatadas entre el Pleistoceno Tardío y Holoceno, con énfasis en diversas estrategias de investigación relacionadas a la identificación de distintas realidades regionales. El hecho de dar a conocer estos avances científicos vinculados con los primeros episodios del Cono Sur de América se fundamenta en la necesidad de estimular la búsqueda de mejores modelos explicativos.

En efecto, en la actualidad se han incrementado las evidencias por parte de reputados investigadores que merecen conocer los distintos modos de aproximación a esta problemática evaluada regionalmente hace ocho años, y que en gran medida se mantienen plenamente vigentes.

Agradecemos a las instituciones ya referidas, que han hecho posible esta edición, y de manera principal a los autores de las ponencias. Por otra parte, se deja constancia del apoyo recibido por las autoridades de esta casa de estudios superiores en torno a la difusión del conocimiento antropológico-arqueológico de algunos de los testimonios humanos más tempranos de esta finis terrae americana.

\section{Lautaro Núñez}

San Pedro de Atacama, septiembre de 1987. 